\title{
Necessidades de cuidados expressas pela família que possui um acamado no domicílio
}

Trata-se de estudo qualitativo descritivo sobre necessidades de cuidados expressas pela família que possui um acamado no domicílio. São objetivos: identificar necessidades de cuidados expressas e analisar quais delas são de cuidados de enfermagem. Envolveu 18 famílias cuja situação financeira foi determinante de muitas necessidades expressas. Três temas revelaram que as famílias tomam para si necessidades do acamado; expressam necessidades próprias financeiras, emocionais, psicológicas; expressam necessidades de cuidados profissionais. Extraíram-se, pela Classificação Internacional das Práticas de Enfermagem, os Focos e Intervenções aplicáveis às necessidades de cuidado que são de enfermagem para o acamado e familiares.

Descritores: Enfermagem, Assistência Domiciliar, Família.

\section{Care needs as expressed by family members who have a bedridden patient at home}

This is a qualitative and descriptive study about the care needs as expressed by family members who have a bedridden patient at home. The objectives are: to identify what care needs are expressed and to analyze, among them, which are related to nursing care. It involved 18 families whose financial situation was a determinant factor for many of the needs expressed. Three topics showed that the families took on their own the care of these patients; they expressed their own financial needs, as well as emotional and psychological needs, and also expressed the need for professional help. In the International Classification of Nursing Practice, the following topic was found: focus and applicable interventions for the necessities of nursing care directly involving the bedridden patient and family.

Descriptors: Nursing, Home Assistance, Family.

\section{Necesidades de cuidados expresadas por la familia que tiene un encamado en el domicilio}

Se trata de un estudio cualitativo y descriptivo sobre las necesidades de cuidados expresadas por la familia que cuenta con un encamado en su domicilio. Los objetivos son: identificar cuáles son las necesidades de cuidados expresadas y analizar cuáles son, entre ellas, cuidados de enfermería. El estudio envuelve 18 familias cuya situación financiera fue determinante para muchas necesidades expresadas. Tres temas revelaron que las familias asumen la responsabilidad por atender a las necesidades del encamado, expresan necesidades propias financieras, emocionales, sicológicas; $y$ expresan necesidades de cuidados profesionales. Fueron extraídos, según la Clasificación Internacional de las Prácticas de Enfermería, los Focos e Intervenciones aplicables a las necesidades de cuidado que son de enfermería, dirigidas a la persona encamada y a sus familiares.

Descriptores: Enfermería, Asistencia Domiciliar, Familia.

\section{INTRODUÇÃO}

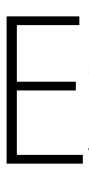

ste trabalho tem como objeto as necessidades de cuidados expressas pela família que possui uma pessoa acamada em seu domicílio, entendendo por necessidade de cuidado tudo aquilo a que família refere como necessário, que deve ser feito, indispensável, algo que precisa e é fundamental para se assegurar de que o familiar acamado esteja sendo bem assistido.

O cuidado domiciliar adequado pode prevenir ou retardar complicações, diminuindo o número de reinternações hospitalares. Por isso, torna-se essencial considerar que, no contexto domiciliar, a presença e atuação qualificada de um familiar é condição fundamental para a implementação de um serviço/cuidado efetivo(1). Sabe-se que muitas pessoas estão gravemente enfermas, cuidadas em suas residências diretamente por um familiar, majoritariamente mulheres na faixa etária de 36 a 62 anos, familiar do ser cuidado, com baixa escolaridade, sem trabalho remunerado e renda familiar entre 1 e 2 salários mínimos ${ }^{(2)}$.

A enfermagem possui, em seu corpo de conhecimento, intervenções que podem auxiliar esse cuidador na organização para cuidar de um enfermo no domicílio. Entende-se o processo de cuidar como um conjunto de ações e comportamentos realizados no sentido de favorecer, manter ou melhorar o processo de viver ou morrer, proporcionando ao paciente

1 Enfermeiro. Mestrando do Programa de Pós-Graduação em Enfermagem/UFAL. Membro do Procuidado/UFAL. E-mail: eduard_araujo@hotmail.com.

2 Enfermeira. Residente de Saúde da Mulher e Obstetrícia da UNCISAL. Membro do Procuidado/UFAL.

3 Enfermeira. Doutora em Enfermagem. Professora Associada II da ESENFAR/UFAL. Líder do GEDIM. Pesquisadora do Procuidado, Coordenadora do Mestrado Enfermagem/UFAL. 4 Enfermeira. Doutora em Enfermagem. Professora Associada II da ESENFAR/UFAL. Líder do Procuidado. Pesquisadora do GEDIM. Docente Permanente do Mestrado Enfermagem/UFAL. 
conforto físico, emocional e espiritual ${ }^{(3)}$.

Considerando tudo o que foi argumentado, compreendendo-se a amplitude da temática e do objeto proposto, tem-se como objetivos: identificar nas falas das famílias que possuem um acamado que necessidades de cuidados são expressas e analisar, nas necessidades expressas, quais são de cuidados de enfermagem.

\section{MÉTODO}

Foi um estudo descritivo qualitativo realizado em 2010. O cenário foi a residência de pessoas com familiares acamados nas cidades de Maceió e Arapiraca/AL. No domicílio, tivemos a vantagem de encontrar a pessoa acamada, os membros significativos da família e seus principais cuidadores. Para encontrar essas famílias, recorremos a três Unidades de Saúde da Família - USF, duas do 70 Distrito Sanitário de Maceió e uma em Arapiraca. Também buscamos o Serviço de Atendimento de Home Care localizado em Maceió.

Os sujeitos estudados foram membros de 18 famílias que têm um acamado, selecionadas abrangendo bairros socioeconomicamente distintos. Foram critérios de inclusão: pessoas com idade superior a 18 anos; pessoas designadas pelo acamado como seu familiar; participantes direta ou indiretamente do cuidado ao doente; pessoas que se dispuseram a participar do trabalho e assinaram o Termo de Consentimento Livre e Esclarecido - TCLE. A técnica de produção dos dados foi a entrevista semiestruturada ${ }^{(4)}$. Após marcar com a família o melhor momento para o encontro, solicitamos permissão para usar um gravador. Quanto à avaliação do material produzido, utilizamos a técnica de análise de conteúdo na modalidade temática ${ }^{(5)}$.

Em respeito à Resolução 196/96, os aspectos éticos foram observados. O projeto foi submetido ao Comitê de Ética da UFAL, tendo sido aprovado no Processo número 027021-201001. O TCLE foi assinado e a família escolheu seu pseudônimo na forma de uma decisão empoderada.

\section{RESULTADOS}

Das 18 entrevistas realizadas, dez aconteceram em Arapiraca e oito em Maceió. Os moradores das residências variaram de 2 a 6 pessoas. As residências possuíam de 2 a 12 cômodos, porém nem sempre o acamado teve um cômodo só para ele. Dessas 18 famílias, 16 apresentam vínculo institucional com a USF enquanto duas estão diretamente vinculadas ao serviço de Home Care. A frequência de visitas profissionais ocorreu em diferentes intervalos de tempo, acontecendo na maioria mensalmente.

Todas as famílias tiveram apoio institucional, exceto uma que expressou: "Ninguém, ninguém vem aqui, ninguém". As visitas foram feitas por Agentes Comunitários de Saúde e um médico, sendo este citado em 15 entrevistas. Outros profissionais foram o dentista, técnicos e auxiliares de enfermagem, fisioterapeuta, nutricionista e enfermeiro, sendo este último citado em nove entrevistas, ou seja, metade das famílias não relata visita domiciliar de enfermeiro.

A maioria das famílias sobrevive com renda de 1 a 3 salários mínimos mensalmente e gasta de 25 a $50 \%$ da renda nos cuidados com os acamados, que se encontram na faixa etária dos 70 anos de idade, sendo a maior parte do sexo feminino. Os principais motivos para estarem acamados foram Acidente Vascular Encefálico e Depressão. O tempo de permanência no leito variou entre 2 meses e 11 anos, estando a maioria na faixa de dois anos. Quanto ao grau de dependência, a maioria possuía grau de dependência III, conforme a RDC n 283/2005. Os familiares que mais cuidam são do sexo feminino, estando a maioria na faixa etária de 50 a 60 anos de idade, confirmando achados de literatura $^{(2)}$. O grau de parentesco foi em sua maioria filhas sem vínculo empregatício que deixaram de trabalhar para cuidar do acamado.

Após a transcrição e leitura exaustiva dos depoimentos foi possível identificar e agrupar os dados extraindo três temas evidentes em todas as entrevistas. São eles: a família expressa as necessidades de cuidado do familiar acamado; a família expressa suas próprias necessidades para cuidar do familiar; a família expressa as necessidades de cuidados profissionais para o acamado.

\section{A família expressa como suas as necessidades de cuidado do familiar acamado}

Nesta unidade temática, ao se referirem aos cuidados que reconhecem serem necessários ao acamado, as famílias mostraram-se preocupadas, descrevendo a forma como cuidam e deixando claro que isso requer tempo, recursos e saberes que nem sempre possuem. Por isso afirmam que são necessidades de cuidado que elas sentem, mesmo que sejam realizados no outro.

A alimentação é citada em todas as falas expressando diversas necessidades, incluindo informação sobre a diversificação dos alimentos, adequação da dieta a doenças como diabetes e hipertensão arterial, como se pode ver: "Nós estamos alimentando ela bem e como ela é diabética tem que cuidar dessa alimentação, porque tem comidas que o diabético não pode". Assim, se tivesse um médico do posto que sempre viesse ver ela e orientar como eu poderia alimentar ela..."(Dona Silva). Ou, como diz Dona Avenca:" [...] a alimentação dele não é igual à minha, a dele é diferente[...]

Outra evidência foi a necessidade da família de locomover o paciente, tirá-lo da cama e levá-lo para outros lugares, porém, percebe-se que para isso muitas vezes precisa-se de uma cadeira para facilitar o transporte. São notórios ainda os transtornos dos familiares durante o acesso aos serviços de saúde, forçando muitas vezes os próprios familiares a cuidar/movimentar empiricamente seu parente. "...o que ficava em primeiro lugar, era uma cadeira, se pudesse, né? Tem vez que ela mesma reclama e diz: 'ah se tivesse uma cadeira eu tava andando'" (Helena, Williane). Ou pode ser observado: "Às vezes eu preciso levar ela no posto, lá é muito complicado pra mim, por que essa doença dela, pra andar com ela você sabe" (Selma).

Identificamos necessidades do familiar para higienizar o acamado, incluindo o banho, na cama ou chuveiro, verificação da temperatura ideal da água, ajuda de outras pessoas para dar 
o banho, trocar roupa e fralda sujas, escovar os dentes, cortar as unhas, manter a roupa limpa e perfumada. Tudo isso foi observado como essencial para o suprimento das necessidades humanas básicas, a saber: "Dar banho nela eu não dou sozinha porque ela é pesada e não posso colocar ela na cadeira, eu só dou banho nela quando chega alguém para me ajudar, pra pegar ela e colocar na cadeira, aí, pronto, dá banho..." (Flávia). "Ele tem um problema, saliva bastante, precisa estar sempre limpando a boca dele, escovo a boca dele, lavo com antisséptico bucal"(Dona Elza).

\section{A família expressa suas próprias necessidades para cuidar do familiar acamado}

Foram muitas as informações produzidas sobre as necessidades expressas pela família relativas às suas próprias carências. Foi necessário um trabalho prévio de organização para que se visualizassem os subtemas contidos nessa temática, a saber: necessidades financeiras, necessidades de cuidados emocionais e psicológicos, necessidade de divisão de responsabilidades e liberdade.

Dentre os insumos mais citados, a fralda é algo extremamente necessário e dispendioso. Essas afirmações bem como as anteriores ficam explicitadas nessas falas: "Éfralda, creme, roupa, é uma coisa que a pessoa tem... o talco e a fralda eu não deixo faltar, embora tenha que ter tudo no dinheirinho... eu também tenho que usar o dinheiro para comprar roupa, comprar um lençol, um chinelo... é muito gasto". (Dona Silva, Dona Lourdes e Rosa D'alia).

Também é mencionada a necessidade de apoio governamental, que possa ajudar esses familiares a cuidar. "Se a gente deixa de trabal har para tomar conta de alguém doente, o certo seria ganhar um salário sei lá, uma ajuda [...] Acho que o governo tem que olhar melhor, eu acho que o governo tem que fazer a parte dele melhor, tem que ver mais as pessoas, a saúde no caso" (Suelly).

Evidenciamos que o cuidador não tem tempo para si devido à sobrecarga do cuidar, levando à diminuição de suas atividades sociais, não tendo férias ou tempo para passear, para visitar familiares ou amigos e para se divertir, como comprova a fala de Catarina: "Deixei de viver a minha vida, pra viver a vida dela" (Catarina). Em situações extremas isolam-se da sociedade e ficam obstinados no cuidado da pessoa dependente.

\section{A família expressa as necessidades de cuidados profissionais para o seu parente acamado}

As falas deste tema expressam a necessidade de acompanhamento profissional para o acamado. São relatados principalmente acompanhamento médico, pois é perceptível a associação da cura aos cuidados médicos. As necessidades de procedimentos, informações, consultas e acompanhamentos rotineiros acabam sendo realizados muitas vezes por outras pessoas e não pela equipe USF, contrariando a diretriz da visita domiciliar, haja vista que todas as famílias são cadastradas na ESF, como se vê: "Assim, se tivesse um médico do posto que sempre viesse ver ela e orientar, assim... aí dava mais uma força pra mim" (Dona Silva).

\section{DISCUSSÃO}

As famílias expressaram aquilo que classificam como necessidades de seu familiar, considerando as especificidades dos acamados. Confirmando a literatura viu-se que as mulheres são as mais acometidas por doenças crônicas, apesar de utilizarem mais os serviços de saúde de maneira preventiva ${ }^{(6,7)}$.

O familiar acamado depende de que Ihe seja oferecida a alimentação adequada, sendo razoável aceitar que essa tarefa é uma fonte de preocupação da família que, no cotidiano, adquire a condição de necessidade de cuidado. Além disso, aceitando que ao cuidador é atribuída a responsabilidade de alimentar o acamado, é dele que se espera a escolha, preparação, oferta e demais cuidados com a alimentação, precisando ser preparado para isso.

Com a Classificação Internacional das Práticas de Enfermagem - CIPE ${ }^{\circledR}$, propusemos diversas intervenções que podem e devem ser executadas pela enfermagem como: orientar o familiar sobre como alimentar; facilitar mobilização; ensinar o familiar a ser auxiliar de marcha para o acamado andar; adequar o transporte à realidade $\mathrm{e}^{(8)}$.

Inúmeros são os problemas enfrentados pelas famílias dos acamados com limitações, sendo um dos principais o acesso aos serviços de saúde. Podem ser citadas quatro dificuldades principais: barreiras físicas e de transporte; acesso limitado a equipamentos e ajudas técnicas; limitação do acesso a medicações e especialistas; dificuldade de acesso a cuidados especiais ${ }^{(9)}$. Embora a necessidade seja do acamado, é o familiar que se movimenta para acessar os benefícios a que ele tem direito e para tanto precisa ser orientado, encaminhado e até acompanhado para concretizá-los.

Reconhece-se que a família acaba tomando como suas as necessidades de cuidado do seu acamado porque the cabe satisfazê-las. Nessas famílias encontramos pessoas envolvidas com o acamado que se ocupam em atender a todas as suas necessidades, afligindo-se quando não sabem ou não podem fazê-lo ${ }^{(10-12)}$. O relato de um familiar sobre o amor como algo necessário, fundamental, para seu ente acamado é perceptível quando ele não expressa necessidade de fraldas, alimentação, recursos materiais e físicos, porque esses já se encontram saciados, logo são necessidades hierarquicamente superadas para esse familiar.

Os familiares estudados mostraram que cuidar de alguém é uma tarefa pesada que acarreta custos físicos e afetivos para quem a executa. $O$ estudo reafirma que a responsabilidade de cuidar de uma pessoa representa uma sobrecarga importante para a pessoa que cuida informalmente, com consequências psicológicas, emocionais, físicas, sociais e financeiras ${ }^{(13-15)}$.

As mudanças no estilo de vida provocadas pela presença de um doente na família podem provocar alterações estruturais na dinâmica dessa família, pois arcar com despesas com tratamento medicamentoso, exames laboratoriais, materiais de higiene, deslocamento para a unidade de saúde, entre outros, representa alterações orçamentárias significativas e a família brasileira, em sua maioria, não possui recursos financeiros para cobri-las, podendo representar cortes no suprimento de outras necessidades ${ }^{(14)}$.

O suporte ao cuidador informal é relevante visto terem 
papel preponderante no cuidado ao acamado. O estado e as solicitações do doente podem absorver todo o tempo do cuidador, diminuindo os contatos sociais e conduzindo-o ao isolamento ${ }^{(16)}$. Essa carga emocional pode estar relacionada à sobrecarga de cuidados dispensada por um único cuidador, exaltando-se as necessidades relacionadas a dividir o cuidado com outra pessoa. A CIPE ${ }^{\circledR}$ possui termos para intervenções nessas necessidades como incentivar a capacidade de participação nos cuidados do familiar; dividir os cuidados do familiar, divertir-se, fazer atividades lúdicas, promover bem-estar ${ }^{(8)}$.

Ainda são necessidades expressas pela família, o apoio profissional que possa orientar os cuidados a serem oferecidos domiciliarmente ao acamado. A família necessita de saberes que possam otimizar e satisfazer as necessidades de seus acamados, além de reforçarem as condutas que estão adequadas e corrigir ou melhorar aquelas que ainda são insuficientes. A família entende que sozinha não consegue cuidar de forma adequada necessitando de apoio, participação e orientação profissional.

A necessidade de cuidados profissionais para o paciente também pode ser considerada uma necessidade de enfermagem pois seus termos são focos da CIPE ${ }^{\oplus}$ e podem ser sugeridas intervenções como: articular com outros profissionais a visita domiciliar semanalmente; discutir junto com a equipe a situação de cada paciente; orientar sua equipe quanto à necessidade da realização dos procedimentos no domicílio; realizar visitas semanalmente aos acamados ${ }^{(8)}$.

\section{CONCLUSÃO}

O estudo permitiu refletir e reconhecer que a família tem necessidades de cuidados que precisam ser prestados pelos profissionais de saúde, envolvendo o apoio que possa orientar as condutas e cuidados a serem oferecidos em casa ao acamado. Importa salientar que o relato das famílias contraria o estatuto da ESF, onde é atividade obrigatória dos profissionais executar visita domiciliar, levando a questionar como está sendo desenvolvida essa estratégia.

Com o auxílio da CIPE $^{\circledR}$ Versão 2.0, identificamos nas necessidades expressas os termos do eixo Foco por serem fenômenos em que a enfermagem interfere e pode propor intervenções que são cuidados de enfermagem. Identificamos que todas essas necessidades possuem um termo na CIPE $^{\circledR}$ para a qual a enfermagem possui diagnósticos e intervenções próprios. Isso implica reconhecer todas as necessidades expressas como também necessidades de enfermagem.

Por fim, os resultados analisados e discutidos permitiram concluir que o conhecimento das atividades de cuidado desenvolvidas no domicílio e das dificuldades enfrentadas pelos familiares do acamado poderá contribuir com a equipe multiprofissional, para que desenvolvam ações pautadas em novas informações, possam reconhecer o que realmente é necessário para ofamiliar que está cuidando e consequentemente para o acamado, pois esse conhecimento servirá para planejar as ações e satisfazer as necessidades relatadas.

\section{Referências}

1. Brondani $C M$, Beuter M. A vivência do cuidado no contexto da internação domiciliar. Rev Gaúcha Enferm. 2009 jun;30(2):206-13.

2. Yueh-Ching C, Li-yeh F, Li-Chan L, Yue-Chune L. Predictors of subjective and objective caregiving burden in older female caregivers of adults with intellectual disabilities. Int Psychogeriatr. 2011;23:562-72.

3. Santos DIFA. As vivências do cuidador informal na prestação de cuidados ao idoso dependente: um estudo no Concelho da Lourinhã [Dissertação]. Lisboa: Universidade Aberta; 2008.

4. Minayo MCS. O desafio do conhecimento: pesquisa qualitativa em saúde. $10^{\text {a }}$ ed. São Paulo: Huatec; 2007.

5. Costa-Junior FM, Maia ACB. Concepções de homens hospitalizados sobre a relação entre gênero e saúde. Psic Teor Pesq. 2009;25(1):55-63.

6. Rabasquinho C, Pereira H. Gênero e saúde mental: uma abordagem epidemiológica. Anal Psicol. 2007;25:439-54.

7. Conselho Internacional de Enfermagem - CIE. Classificação internacional

para a prática de enfermagem. Versão 2.0 São Paulo: Algol; 2010.

8. Castro SS. Acessibilidade de pessoas com deficiência a serviços de

saúde em áreas do Estado de São Paulo - Projeto AceSS [Tese]. São Paulo:
Universidade de São Paulo; 2010.

9. Neves RS. Sistematização da Assistência de Enfermagem em Unidade de Reabilitação segundo o Modelo Conceitual de Horta. Rev Bras Enferm. 2006 jul-ago;59(4):556-9.

10. Leopardi MT. Teorias em enfermagem: instrumentos para a prática. Florianópolis: NFR/UFSC/Papa-livros; 1999.

11. Horta WA. Processo de enfermagem. São Paulo: EPU; 1979.

12. Pereira MFC. Cuidadores informais de doentes de Alzheimer: sobrecarga física, emocional e social e psicopatologia [Dissertação]. Lisboa: Instituto de Ciências Biomédicas Abel Salazar - ICBAS ; 2007.

13. Silva LF, Guedes MVC, Moreira RP, Souza ACC. Doença crônica: o

enfrentamento pela família. Acta Paul Enferm. 2002;15(1):40-7.

14. Haley WE. Family Caregivers of elderly patients with cancer:

understanding and minimizing the burden of care. J Support Oncol.

2003;1(Suppl 2):25-9.

15. Amendola F, Oliveira MAC, Alvarenga MRM. Influência do apoio social na

qualidade de vida do cuidador familiar de pessoas com dependência. Rev

Esc Enferm USP. 2011;45(4):884-9. 